\title{
BMJ Global Health Integrating community-based verbal autopsy into civil registration and vital statistics: lessons learnt from five countries
} Sonja Margot Firth (D) , John D Hart, ${ }^{1}$ Matthew Reeve, ${ }^{1}$ Hang Li, ${ }^{1}$ Lene Mikkelsen, ${ }^{1}$
Deborah Carmina Sarmiento, ${ }^{1}$ Khin Sandar Bo, ${ }^{1}$ Viola Kwa, ${ }^{1}$ Jin-Lei Qi, ${ }^{2}$ Peng Yin, ${ }^{2}$
Agnes Segarra, ${ }^{3}$ Ian Riley, ${ }^{1}$ Rohina Joshi ${ }^{4,5}$
To cite: Firth SM, Hart JD, Reeve M, et al. Integrating community-based verbal autopsy into civil registration and vital statistics: lessons learnt from five countries. BMJ Global Health

2021;6:e006760. doi:10.1136/ bmjgh-2021-006760

Handling editor Seye Abimbola

Received 29 June 2021

Accepted 12 0ctober 2021

Check for updates

C) Author(s) (or their employer(s)) 2021. Re-use permitted under CC BY-NC. No commercial re-use. See rights and permissions. Published by BMJ.

${ }^{1}$ School of Population and Global Health, The University of Melbourne, Melbourne, Victoria, Australia

${ }^{2}$ National Center for Chronic and Noncommunicable Disease Control and Prevention, Chinese Center for Disease Control and Prevention, Beijing, China ${ }^{3}$ Epidemiological Bureau, Republic of the Philippines Department of Health, Manila, Philippines

${ }^{4}$ The George Institute for Global Health, Newtown, New South Wales, Australia

${ }^{5}$ The George Institute for Global Health India, New Delhi, Delhi, India

Correspondence to

Sonja Margot Firth;

sonja.firth@unimelb.edu.au

\section{ABSTRACT}

This paper describes the lessons from scaling up a verbal autopsy (VA) intervention to improve data about causes of death according to a nine-domain framework: governance, design, operations, human resources, financing, infrastructure, logistics, information technologies and data quality assurance. We use experiences from China, Myanmar, Papua New Guinea, Philippines and Solomon Islands to explore how VA has been successfully implemented in different contexts, to guide other countries in their VA implementation. The governance structure for VA implementation comprised a multidisciplinary team of technical experts, implementers and staff at different levels within ministries. A staged approach to VA implementation involved scoping and mapping of death registration processes, followed by pretest and pilot phases which allowed for redesign before a phased scale-up. Existing health workforce in countries were trained to conduct the VA interviews as part of their routine role. Costs included training and compensation for the VA interviewers, information technology (IT) infrastructure costs, advocacy and dissemination, which were borne by the funding agency in early stages of implementation. The complexity of the necessary infrastructure, logistics and IT support required for VA increased with scale-up. Quality assurance was built into the different phases of the implementation. VA as a source of cause of death data for community deaths will be needed for some time. With the right technical and political support, countries can scale up this intervention to ensure ongoing collection of quality and timely information on community deaths for use in health planning and better monitoring of national and global health goals

\section{INTRODUCTION}

Verbal autopsy (VA) is a method for obtaining the cause of death in cases where a physician was not present and it is not possible to produce a medical certificate of cause of death (MCCOD). VA involves an interview with close relatives or caregivers of the deceased on the signs and symptoms that
Summary box

Verbal autopsy (VA), a validated method for understanding the causes of out-of-hospital death, is now being scaled up as part of civil registration and vita statistics (CRVS) in many low-income and middleincome countries.

- Implementing VA in CRVS is a complex intervention requiring a strong governance structure backed by technical expertise, infrastructure, logistics, information technology and human resources with appropriate evaluation and adaptation throughout the implementation phases.

- Stakeholders need to consider the system-level changes - and ongoing costs-necessary to embed the intervention before embarking on VA implementation.

- VA will improve information on causes of community death, thereby improving health system planning and monitoring of national and international health goals.

were present prior to death, and an assignment of cause of death either by physician review or, more efficiently, using computer algorithms. ${ }^{2}$ This paper describes the use of the 'SmartVA' method, which comprises the Population Health Metrics Research Consortium shortened VA instrument, combined with the SmartVA-Analyze software, which uses the Tariff V.2.0 computer algorithm to assign cause of death from VA. ${ }^{34}$

Advances in VA methods have made it possible to collect information on non-facility death as part of routine systems - and as a component of efforts to improve civil registration and vital statistics (CRVS) - so that they can be used for policy and planning purposes. This is particularly important in countries where non-facility deaths constitute the majority of deaths. ${ }^{5}$ Since integrating VA 
into CRVS systems is a relatively new undertaking, it is important to understand the system-level requirements during scale-up. The Bloomberg Philanthropies Data for Health Initiative (D4H) is a public health initiative that aims to improve data for policy in low-income and middle-income countries. An important aspect of the work was to ascertain likely causes of community deaths using VA. The initiative used a systems lens ${ }^{6}$ to plan and implement the roll-out across a number of countries globally, outlined by de Savigny et $a l^{7}$, and has had a significant impact on policy and practice..$^{8-13}$

This paper describes the lessons learnt over the last 5 years using de Savigny et al s framework, which lays out the system-level features that need to be considered for the successful implementation of VA under domains of governance, design, operations, human resources, financing, infrastructure, logistics, information technologies and data quality assurance. ${ }^{7}$ We use experiences from the roll-out in China, Myanmar, Papua New Guinea (PNG), Philippines and Solomon Islands, to explore how VA was successfully implemented in these different contexts to guide other countries planning large-scale VA implementation.

\section{GOVERNANCE}

For countries implementing VA as part of D4H CRVS, a common imperative was understanding the causes of community death. All five countries are signatories to the United Nation's Sustainable Development Goals to improve the notification, registration and causes of deaths by 2030. These targets align with the WHO's call for universal civil registration of births and deaths, including causes of death, the World Bank CRVS targets and the United Nation's Economic and Social Commission for Asia and the Pacific. ${ }^{14} 15$

Table 1 outlines the details of governance for VA implementation in each country. The VA intervention was co-designed with government partners to ensure that there was the strong government buy-in necessary for implementing such a complex intervention. Each country (except China, where China Centres for Disease Control oversaw the VA pilot) had an interagency committee responsible for CRVS strengthening. For some countries, partnering with $\mathrm{D} 4 \mathrm{H}$ was an opportunity to establish (eg, Solomons) or reinvigorate (eg, Myanmar and PNG) the CRVS committees, which included a heterogenous group of agencies, with sometimes divergent agendas. VA 'focal points' in each agency facilitated the VA implementation process and necessary interagency collaborations. Working within some country government structures presented challenges. In the Solomon Islands, the national CRVS governance structure has little provincial representation and barriers to communication with provinces continuing to present challenges in the implementation of VA. In all countries, high senior staff turnover meant it was important to have work plans in place, regular meetings to ensure continued support and a technical working group-which was assembled in all sites-comprising mid-ranking staff, to build capacity, provide local knowledge and preserve continuity. Advocacy needed to be built into the implementation process to convince all stakeholders. ${ }^{16}$ Figure 1 illustrates a generic governance structure for VA, and the responsibilities of the different stakeholders and committees from the national level down to the frontline workers.

While country-led, the team from $\mathrm{D} 4 \mathrm{H}$ provided technical support on VA implementation, monitoring and evaluation. This included discussions with country officials on implementation strategy, training, information technology (IT) requirements, and guidance on how to interpret and use the information coming from VA. ${ }^{17-19}$ The country team was encouraged to assume the technical responsibility and tasks, as their capacity increased and the VA roll-out progressed. This capacity transfer was more advanced in countries at later stages of implementation (eg, Myanmar) and countries where existing capacity was higher (eg, Philippines and China).

\section{DESIGN AND OPERATIONAL ISSUES}

A staged approach was necessary for VA implementation involving scoping and mapping of death registration processes, followed by pretest and pilot phases which allowed for redesign before a phased scale-up. This facilitated gradual confidence-building at all levels of government as they gained capabilities and evidence of the benefits of VA. The need to go at the pace set by the government, and the time needed for changes to legislation impacted the implementation strategy in each country. In Myanmar, government partners wanted to demonstrate that VA could be conducted anywhere so that system changes could be institutionalised. This resulted in rapid scale-up of the intervention from a pretest in three townships in 2016, a pilot in 14 townships in 2017 to 42 townships across the country from $2018 .^{20}$ In PNG, the delay in the Civil Registration Bill and the subsequent endorsement of VA as a tool to determine community cause of death has resulted in slow changes on the ground. In the meantime, cultivating good relationships with staff at all levels of government has been necessary to ensure implementation does not stall. Design and operational issues for each country are outlined in table 2 .

\section{Understanding the processes in death registration}

Business process mapping (BPM) to detail death registration processes was used to design the VA implementation. BPM can facilitate mutual understanding between stakeholders, can be used to identify bottlenecks and inefficiencies in the existing system, and galvanise support for change. ${ }^{21}$

The complexity of the BPM activity ${ }^{21}$ and the different stakeholders to be consulted posed significant challenges. Where senior staff noted 'correct' (rather than 'actual') procedures, field staff did not feel confident to contradict this. Preliminary mapping sessions were needed with 
Table 1 Description of country governance for VA implementation

\begin{tabular}{|c|c|c|c|c|}
\hline \multirow[t]{2}{*}{ Country } & \multirow[t]{2}{*}{$\begin{array}{l}\text { Aim of the VA } \\
\text { intervention }\end{array}$} & \multicolumn{3}{|l|}{ Governance of VA implementation } \\
\hline & & $\begin{array}{l}\text { National CRVS policy and coordinating } \\
\text { committee }\end{array}$ & $\begin{array}{l}\text { National subcommittee/technical } \\
\text { working group on mortality and } \\
\text { cause of death }\end{array}$ & $\begin{array}{l}\text { Business case/rationale for } \\
\text { VA implementation }\end{array}$ \\
\hline China & $\begin{array}{l}\text { To explore the feasibility } \\
\text { of using VA to improve } \\
\text { the quality of community } \\
\text { cause of death data }\end{array}$ & $\begin{array}{l}\text { No CRVS committee Chinese CDC } \\
\text { responsible for VA pilot studies }\end{array}$ & $\begin{array}{l}\text { Chinese Centre for Chronic and } \\
\text { Noncommunicable Disease } \\
\text { Control and Prevention, of } \\
\text { Chinese CDC }\end{array}$ & $\begin{array}{l}\text { The current procedure for } \\
\text { capturing community cause } \\
\text { of death was not standard } \\
\text { and needed improvement. }\end{array}$ \\
\hline Myanmar & $\begin{array}{l}\text { To produce nationally } \\
\text { representative data on } \\
\text { community cause of } \\
\text { death in the country. }\end{array}$ & $\begin{array}{l}\text { Coordinating committee for birth } \\
\text { and death registration was in } \\
\text { existence. } \\
\text { Members include } \\
\text { Ministry of Health and Sport. } \\
\text { Ministry of Education. } \\
\text { Ministry of Home Affairs. } \\
\text { Ministry of Labour, Immigration } \\
\text { and Population. } \\
\text { Office of the Attorney General. } \\
\text { Ministry of Planning and Finance. } \\
\text { Ministry of Social Welfare, Relief } \\
\text { and Resettlement. } \\
\text { Ministry of Communication and } \\
\text { Information Technology. } \\
\text { Ministry of Livestock, Fisheries } \\
\text { and Rural Development. }\end{array}$ & $\begin{array}{l}\text { Mortality technical working } \\
\text { group was created to oversee } \\
\text { the VA implementation as well } \\
\text { as other CRVS strengthening } \\
\text { activities. } \\
\text { Members include } \\
\text { Central Statistical } \\
\text { Organisation. } \\
\text { Ministry of Health and } \\
\text { Sports. } \\
\text { General Administration } \\
\text { Department. }\end{array}$ & $\begin{array}{l}\text { Critical information } \\
\text { on majority ( } 84 \%) \text { of } \\
\text { deaths occurring outside } \\
\text { a facility is missing } \\
\text { (either through low } \\
\text { registration or very poor- } \\
\text { quality cause of death). } \\
\text { Hospital cause of } \\
\text { death is biased and } \\
\text { does not provide } \\
\text { good information on } \\
\text { population cause of } \\
\text { death patterns in the } \\
\text { country. }\end{array}$ \\
\hline PNG & $\begin{array}{l}\text { To improve the quality } \\
\text { of cause of death data } \\
\text { in defined mortality } \\
\text { surveillance sites }\end{array}$ & $\begin{array}{l}\text { Dormant CRVS committee was } \\
\text { re-established, cochaired by the } \\
\text { registrar-general and the manager } \\
\text { of the Performance Monitoring and } \\
\text { Research Branch at the National } \\
\text { Department of Health. } \\
\text { Members include } \\
\text { Development partners } \\
\text { DFAT. } \\
\text { WHO. } \\
\text { World Bank. } \\
\text { UNFPA. } \\
\text { UNICEF. } \\
\text { Government stakeholders } \\
\text { National Department of Health. } \\
\text { Department for National Planning } \\
\text { and Monitoring. } \\
\text { Department of Provincial and } \\
\text { Local Government Affairs. } \\
\text { National Statistics Office. } \\
\text { Department of Justice and } \\
\text { Attorney General. } \\
\text { National Department of } \\
\text { Community Management. }\end{array}$ & $\begin{array}{l}\text { National Burden of Disease } \\
\text { Technical Committee, reports to } \\
\text { the secretary for health and the } \\
\text { Medical Society of PNG. } \\
\text { Members include } \\
\text { National Department of } \\
\text { Health. } \\
\text { School of Medicine and } \\
\text { Health Sciences, University } \\
\text { of PNG. } \\
\text { Institute of Medical Research } \\
\text { staff. } \\
\text { Senior physicians and } \\
\text { hospital directors. }\end{array}$ & $\begin{array}{l}\text { Critical information, } \\
\text { including fact of death } \\
\text { as well as cause of } \\
\text { death, was missing for } \\
\text { most deaths occurring } \\
\text { outside of health } \\
\text { facilities. }\end{array}$ \\
\hline Philippines & $\begin{array}{l}\text { To improve the quality of } \\
\text { the cause of community } \\
\text { deaths nationally using } \\
\text { SmartVA for Physicians } \\
\text { (using SmartVA as a } \\
\text { decision support tool } \\
\text { to certify deaths by } \\
\text { physicians) }\end{array}$ & $\begin{array}{l}\text { Interagency committee on civil } \\
\text { registration and vital statistics } \\
\text { existed. } \\
\text { Chair: Philippine Statistics Authority } \\
\text { Vice chair: Department of Health } \\
\text { Members include } \\
\text { Department of Foreign Affairs. } \\
\text { Department of Justice. } \\
\text { Department of Education. } \\
\text { Department of Social Welfare } \\
\text { and Development. } \\
\text { Department of Interior and Local } \\
\text { Government. } \\
\text { Office of the Cabinet Secretary. } \\
\text { Population Commission. }\end{array}$ & $\begin{array}{l}\text { At first a technical advisory } \\
\text { group for VA was established to } \\
\text { provide guidance. } \\
\text { Later, the epidemiology bureau } \\
\text { at the Department of Health } \\
\text { took over the training and } \\
\text { implementation of SmartVA. }\end{array}$ & $\begin{array}{l}\text { The quality of cause of } \\
\text { death data for the deaths } \\
\text { occurring outside of } \\
\text { health facilities needed } \\
\text { improvement. }\end{array}$ \\
\hline
\end{tabular}


Table 1 Continued

\begin{tabular}{|c|c|c|c|c|}
\hline Country & $\begin{array}{l}\text { Aim of the VA } \\
\text { intervention }\end{array}$ & Governance of VA implementation & & \\
\hline $\begin{array}{l}\text { Solomon } \\
\text { Islands }\end{array}$ & $\begin{array}{l}\text { To achieve national } \\
\text { coverage of community } \\
\text { deaths and deaths-on- } \\
\text { arrival at health facilities }\end{array}$ & $\begin{array}{l}\text { A national CRVS committee } \\
\text { was established, comprising } \\
\text { representatives from the Ministry of } \\
\text { Health and Medical Services, and } \\
\text { Ministry of Home Affairs }\end{array}$ & $\begin{array}{l}\text { A national mortality technical } \\
\text { working group was established, } \\
\text { primarily comprising senior } \\
\text { clinicians, health information } \\
\text { management staff and health } \\
\text { policy makers. }\end{array}$ & $\begin{array}{l}\text { Critical information, } \\
\text { including fact of death as } \\
\text { well as cause of death, was } \\
\text { missing for the majority of } \\
\text { deaths occurring outside of } \\
\text { health facilities. }\end{array}$ \\
\hline
\end{tabular}

Chinese CDC, Chinese Center for Disease Control and Prevention; CRVS, civil registration and vital statistics strengthening; DFAT, Department of Foreign Affairs and Trade; PNG, Papua New Guinea; UNFPA, United Nations Population Fund; VA, verbal autopsy.

staff at different government levels and agencies before presentation and discussion with senior staff. In addition, necessary procedural differences between regions sometimes resulted in hybrid versions of maps. For example, in Myanmar and Solomon Islands, a burial permit is required for community deaths that happen in urban (but not rural) areas. In the Philippines, a death must be registered before the deceased can be buried, excepting Muslim areas, and hence registration (and VA) must happen within 24-48 hours.

\section{Sampling and scale-up design for Va}

Most jurisdictions conduct VA on a sample of deaths to understand population cause of death patterns. ${ }^{7}$ Strict scientific methods to obtain robust information need to be balanced with operational considerations. To establish 'proof of concept', countries were encouraged to choose a convenience sample of sites considered more likely to succeed, or those with sufficient number of deaths. See for details regarding sampling. The biases introduced due to purposeful sampling need to be accounted for, especially when analysing the data to obtain national cause of death patterns.

\section{Community operational considerations}

The characteristics of some sites presented further considerations to VA implementation (see table 2). For remote areas, some changes to procedures around tablet use (PNG) and data collection and upload as well as supervision (Solomon Islands) were necessary. In China, for Tibet and Chongqing, the investigator asked the questions in local dialect. In Myanmar, midwives were trained in the correct procedure for death registration as well as VA, since they represented two separate and parallel activities.

\section{Adaptation of the intervention}

Country ownership of the VA intervention was encouraged, and adaptations were necessary to ensure the VA implementation served its needs in all sites (see table 3). One of the more significant adaptations was to accommodate the mandate in the Philippines that physicians fill

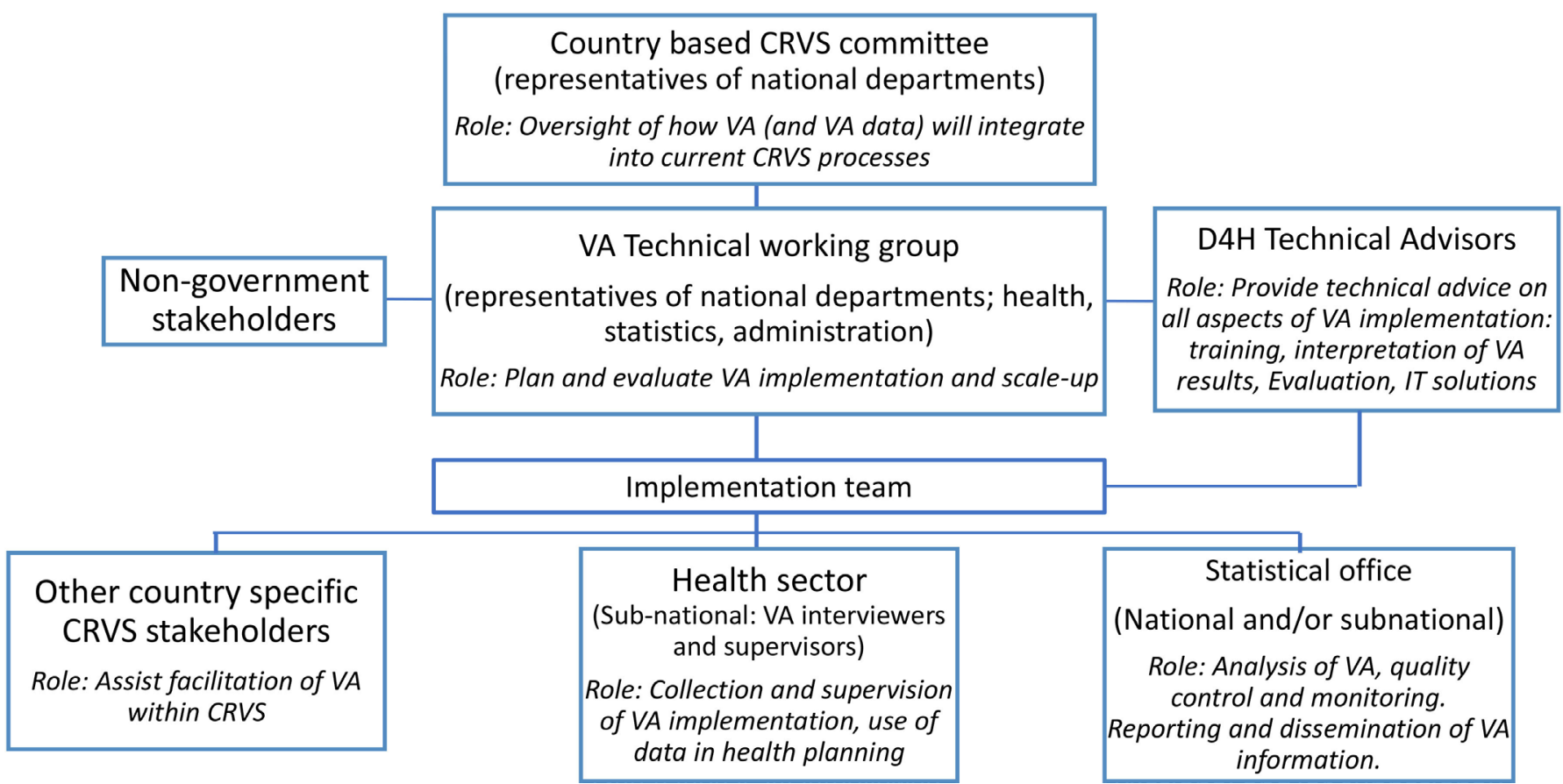

Figure 1 Generic governance structure for D4H VA implementation. CRVS, civil registration and vital statistics strengthening; D4H, Bloomberg Philanthropies Data for Health Initiative; VA, verbal autopsy. 


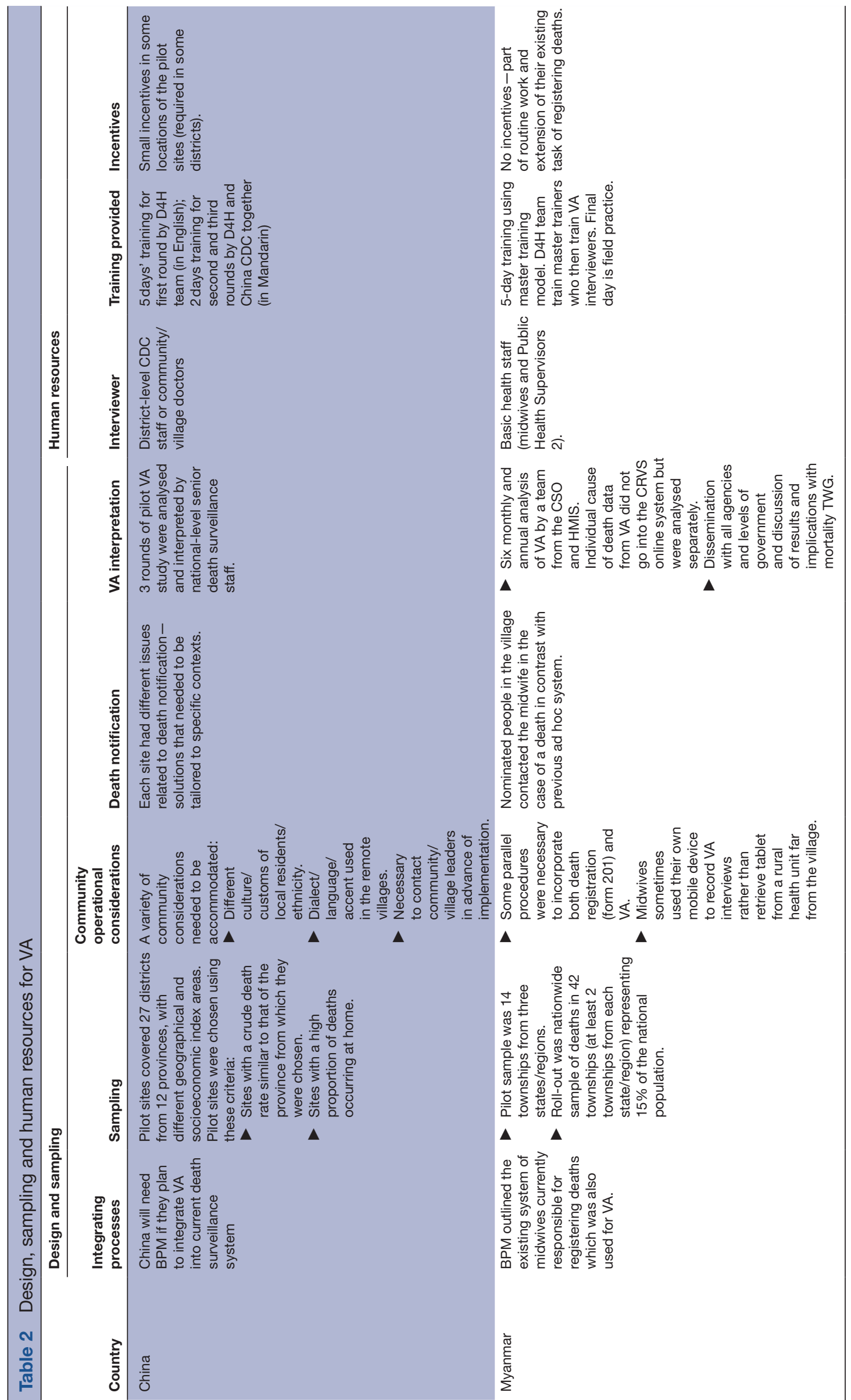

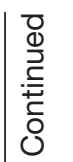




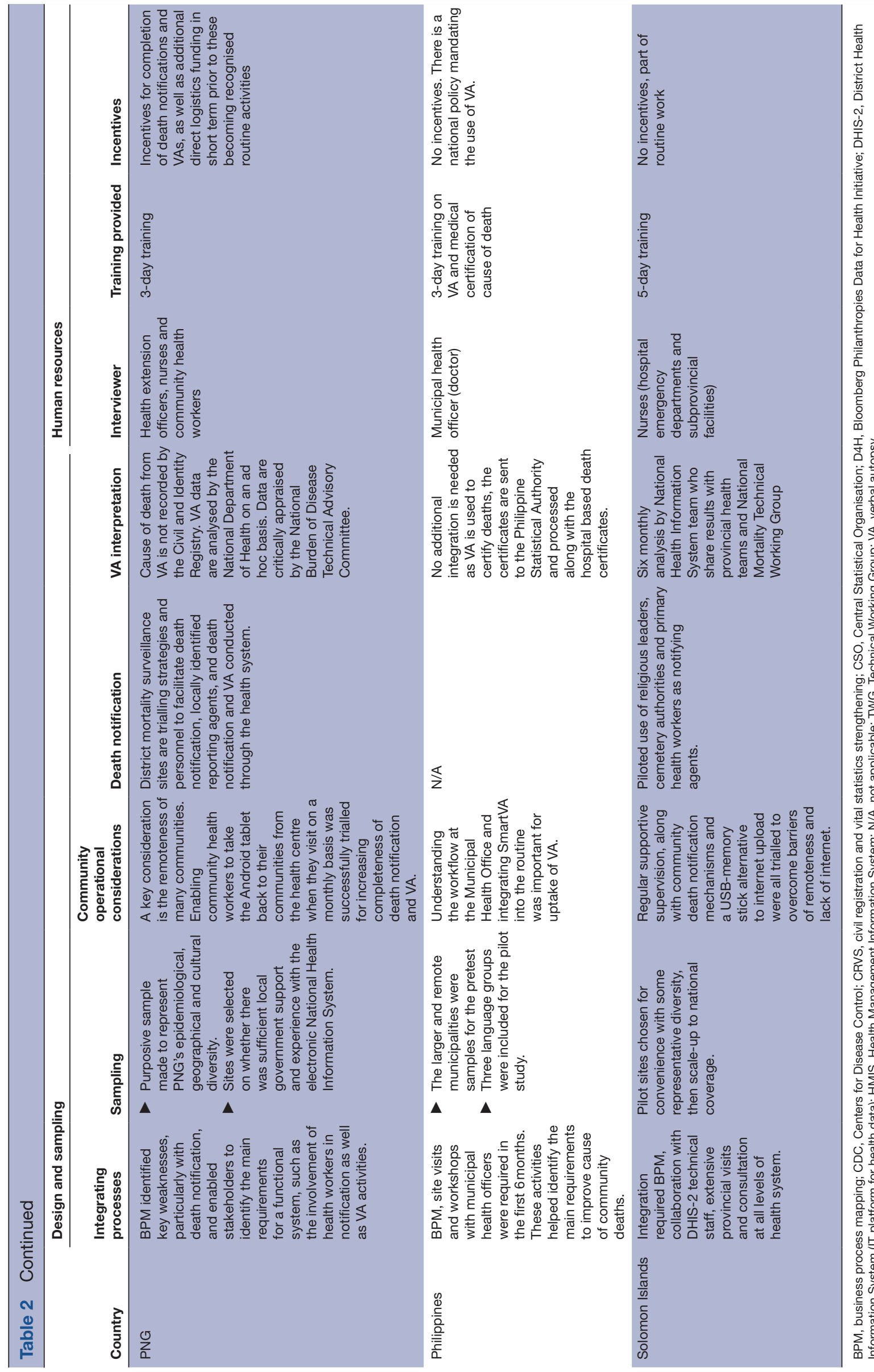




\begin{tabular}{|c|c|c|}
\hline Country & Need & Adaptation \\
\hline Philippines & $\begin{array}{l}\text { MCCOD by physicians is mandated for all deaths, not just those that } \\
\text { occur in hospitals. }\end{array}$ & $\begin{array}{l}\text { SmartVA was adapted for physicians and a novel application of } \\
\text { VA called 'SmartVA for Physicians' was introduced. Here doctors } \\
\text { use SmartVA as a tool for medical certification in the event of a } \\
\text { community death. }\end{array}$ \\
\hline PNG & $\begin{array}{l}\text { 'Dead on arrival' cases assigned to 'unknown' or unusable cause on } \\
\text { the MCCOD }\end{array}$ & $\begin{array}{l}\text { SmartVA for Physicians was introduced for dead on arrival cases } \\
\text { (similar to the Philippines model). }\end{array}$ \\
\hline $\begin{array}{l}\text { Solomon } \\
\text { Islands }\end{array}$ & $\begin{array}{l}\text { Dead on arrival cases were not assigned a cause of death as } \\
\text { physician certification was reserved for patients who were admitted } \\
\text { or who had significant physician contact before/on arrival at } \\
\text { hospital. }\end{array}$ & $\begin{array}{l}\text { VA for dead on arrival cases was provided by nurses so that these } \\
\text { cases could be assigned a cause of death. }\end{array}$ \\
\hline Myanmar & $\begin{array}{l}\text { Information from MCCOD ( } 16 \% \text { of deaths) was used for annual } \\
\text { population statistics. With increased community cause of death } \\
\text { information from VA the government requested technical assistance } \\
\text { to combine the data to obtain more representative estimates. }\end{array}$ & $\begin{array}{l}\text { VA cause of death and MCCOD data were integrated for inclusion } \\
\text { in the Myanmar Annual Statistical Yearbook. A workshop } \\
\text { was held for the D4H team to capacitate staff to do this and } \\
\text { to produce baseline values for non-communicable disease } \\
\text { indicators for Sustainable Development Goals. }\end{array}$ \\
\hline China & $\begin{array}{l}\text { Researchers wished to investigate if COVID-19 related questions in } \\
\text { VA could reliably predict this disease as a cause of death and the } \\
\text { relationship between smoking and COVID- } 19 \text { mortality. }\end{array}$ & $\begin{array}{l}\text { Following pilots of the standard SmartVA questionnaire, questions } \\
\text { were added to the SmartVA interview related to COVID-19, } \\
\text { disease exposure and to tobacco use. This was tested against } \\
\text { known hospital cases of COVID-19. }\end{array}$ \\
\hline
\end{tabular}

D4H, Bloomberg Philanthropies Data for Health Initiative; MCCOD, medical certification of cause of death; VA, verbal autopsy.

out a MCCOD for all deaths, even those in the community. SmartVA was adapted so that it could be used by physicians as an aid to assigning an individual cause of death at the time of interview, called 'SmartVA for Physicians'. ${ }^{10}$ In PNG, SmartVA for Physicians is being trialled in hospitals for dead-on-arrival cases. Other adaptions to VA implementation included changes to mortality analysis (Myanmar) ${ }^{19}$ and testing changes to the questionnaire to incorporate additional questions related to COVID-19 (China). All adaptations were aimed at increasing the uptake and relevance of the VA intervention in the specific country context.

\section{Death notification}

A necessary first step to capture a mortality event, notification of death is in most countries a passive event, relying on family members to report to authorities, which they typically do not do. Multiple notification strategies in PNG included trials of paper and electronic methods and engaging different cadres of notification agent. ${ }^{22} \mathrm{~A}$ key recommendation in both PNG and Myanmar was to identify a community reporting agent tasked with alerting relevant authorities about deaths. ${ }^{23}$ In the Solomon Islands, three death notification strategies were piloted, using religious leaders, cemetery administrators and primary health staff as notifying agents. In using primary health staff, a paper version of the VA questionnaire was used so that interviews could be conducted when informants were available, and data were later digitised by the visiting supervisor. Improving notification is a common need, but methods by which this can be done are context specific and are best designed and tested using BPM.

\section{VA interpretation}

The primary use of VAs to provide population cause of death patterns dominates the need to record the individual cause for each death, as required by the CRVS system in many countries. To facilitate the primary purpose of VA in some D4H countries, analysis of VA was performed outside the CRVS system on populationlevel data for use in health planning, for instance, by the National Department of Health in PNG and the Ministry of Health and Medical Services in Solomon Islands. In China, VA data were analysed by the senior death surveillance staff from national level (Chinese Center for Disease Control and Prevention) with data analysed at both the national and province levels. ${ }^{24}$ In the Philippines, the redesign of SmartVA meant that the cause of death is directly added to the MCCOD, which is integrated into the CRVS system used to produce vital statistics. ${ }^{10}$ In Myanmar, the joint analysis of VA by the Central Statistical Organisation (CSO) and the Health Management Information System (HMIS) has facilitated the inclusion of VA information from 2018 and 2019 in their Annual Vital Statistics Report. ${ }^{195}$

Since the stage of country implementation of VA differs, the interpretation of results was also tailored to reflect the plausibility of the results at either national, regional or pilot phase. Guidance and tools were developed for this purpose. ${ }^{17} 18$ Results from VA in the five countries and their interpretation have been reported elsewhere and were found to be useful and plausible. ${ }^{5-10} 2024$

\section{HUMAN RESOURCES}

VA is designed to be conducted by non-physicians and a key concern is the acceptability and familiarity of the VA interviewer to the family member of the deceased. In each country, the most appropriate staff were chosen after stakeholder consultation and mapping of death registration processes (see table 2). For example, doctors (mandated to certify deaths) were used in the Philippines, whereas midwives were ued in Myanmar because of their existing role in registering deaths. All classes of health 
workers were found to be competent in VA methods when appropriately trained. To promote sustainability, the existing health workforce in countries were trained to conduct the VA interviews as part of their routine role. Supervisors, often master trainers, were responsible for both ensuring data quality and helping interviewers deal with difficult issues arising from the interview, and therefore were also needed to be trained appropriately. VA training can be lengthy (usually 5 days) and staff turnover meant continuous training of new staff in addition to refresher training for existing staff. Keeping a register of staff changes was essential to understanding training needs. In Myanmar, the most advanced country in terms of roll-out, several rounds of refresher trainings became challenging with scale-up due to the number and geographical spread of staff. Myanmar has integrated VA training into the preservice curriculum in midwifery schools and schools of community health to familiarise new staff with the methods, although on-the-job training to consolidate skills will still be needed. In the Philippines, where doctors mostly do the interview, continued professional development points are being considered as an incentive for VA training. In the Solomon Islands, a small population meant that many VA data collectors encountered only two to three deaths per year, which made it difficult to maintain VA skills without refresher training.

Staff motivation-a concern when introducing new tasks to an existing workforce-was promoted in a number of ways across the countries. In PNG, remuneration in the form of monetary incentives was introduced at early stages of implementation to help institutionalise VA. In Myanmar and PNG, information from VA was disseminated to frontline staff as motivation and to illustrate the impact of their efforts-also providing an opportunity to address data quality and operational issues raised by VA implementors.

The COVID-19 pandemic added to the workload; priorities shifted in health ministries; and VA was disrupted in most sites. In cases where VA interviewers were not welcomed into homes, preserving the notification of death, often by telephone, was prioritised, so that VA could be conducted later. The pandemic necessitated a shift to online training, which, where internet allows, provides a potential model for refresher training. While online training can increase the number of participants, without associated travel costs, we found that the complexity of the VA intervention and related training suggests that hybrid methods (online and face-to-face) will be necessary to ensure full competency.

\section{FINANCING ISSUES}

Costs involved in incorporating VA in CRVS systems included training and compensation for the VA interviewers, IT infrastructure costs (to receive, manage and transfer data, and to purchase tablets or other hardware), advocacy and dissemination. For such projects, many upfront costs are borne by the funding agency, with governments offering in-kind support. However, as the scale-up continues, governments are expected to start using their own funds. Costing tools for VA implementation have been developed and applied in countries. ${ }^{26}{ }^{27}$ However, governments are often not keen to address costing concerns while the intervention is still under trial and donor-supported. A systems lens should be used when considering financing for VA since possibilities to integrate some of these costs with other programmes may exist. For example, in the Solomon Islands, VA refresher training is frequently incorporated into provincial training visits by a team including health information system technical staff, representatives of the civil registry and development partners supporting vertical health programmes. In most Solomon Islands facilities, the digital tablet used for VA was the first device issued to the facility and is available for use by other programmes to increase mutual sustainability. If the device for recording the interview is used for other work purposes and other people, it is important to ensure there are enough devices available to avoid delays.

Short funding cycles present another challenge in the implementation of projects requiring system change. Usually, donors fund projects for 4-5years (often in tranches) during which detailed stakeholder consultations involving codevelopment of the intervention, pilot and scale-up are often expected. Implementers usually require more than 5-year funding cycles for such system-wide changes, and essential preliminary steps in the implementation process may be rushed to be able to demonstrate progress before the funding cycle ends.

\section{INFRASTRUCTURE, LOGISTICS AND INFORMATION TECHNOLOGY ISSUES}

The complexity of the necessary infrastructure and logistics of conducting VA increases with scale-up, and different challenges emerged as new sites are added. In Myanmar, some townships are inaccessible for part of the year (due to seasonal flooding), resulting in a longer gap between a death and the VA interview than for other sites, which is acceptable up to a year after death. ${ }^{28}$ Staff sometimes used their own mobile devices to conduct the VA interview and transferred this information into a VA questionnaire on a tablet at their monthly supervisory meeting, a pragmatic solution when tablets are held in subhealth units far from the village, which may nonetheless introduce data entry errors.

IT infrastructure can also be a challenge. VA interviews can be done off-line but require the internet to send the data to a central server for analysis. In the Solomon Islands, some sites had no mobile internet coverage for uploading VA data, so the data needed to be regularly saved to a tablet-compatible USB memory device and delivered via boat to the subprovincial facility for uploading. In PNG, poor internet connection was common and tablets were configured to upload as soon 
as a mobile or wi-fi signal was available. Issues with tablet breakage and loss have been surprisingly rare in PNG following a strategy of assigning responsibility to a single member of staff for each device. In Myanmar, the township CSO was trained to assist with IT and tablet issues. In some areas of China, death surveillance data are analysed and compiled using older versions of Windows, whereas SmartVA tools rely on Windows 7 and above. Upgrading of computers in some areas will be needed before VA can be incorporated into the current death surveillance system.

IT advances have a role in facilitating long-term sustainability in the use and sharing of data. In PNG, the VA team has been collaborating with the developers of the electronic National Health Information System, which plans to incorporate the death notification data for all births and deaths known to the health system and completion of either VA or MCCOD, as appropriate. In Solomon Islands, VA results are currently manually entered into the District Health Information System (IT platform for health data) Tracker database, and a draft tool for automatic importation of these results has been developed. The Philippine model of SmartVA for Physicians presented unique challenges. The emulator installed to facilitate conducting the interview and analysis on one device also raised issues related to the slowness of the software especially if the computer is dated. Alternative solutions are being sought. Another issue is in the distribution of updates to doctors conducting SmartVA for Physicians. Unlike the traditional use of VA, where tablets are linked to a central server, doctors needed to be informed and to manually download new versions.

These IT developments rely on local staff capable of providing ongoing support for server hosting, system maintenance and trouble-shooting, who are not always available.

\section{QUALITY ASSURANCE}

Quality assurance is integral to the scale-up process and needs to be built into the different phases of the implementation and be everybody's concern rather than just a concern for the statistician at the end point. The many competing priorities of staff, including data collectors, supervisors and those at the ministry level, should be considered carefully.

In the Philippines, more support and monitoring must be provided for overworked doctors who have limited time to perform interviews, resulting in high proportions of undetermined causes of death. Process evaluation during the pretest and pilot phase have led to several changes in the tool used (from standard SmartVA to SmartVA for physicians) to better suit those using it and a strict standard operating procdedure. In some busy centres, non-physicians (nurses and nutrition officers) have been tasked with undertaking the VA interview before review and certification by a physician. However, a major challenge has been the
Box 1 Recommendations for scale-up of VA into CRVS

- Strong governance and business case: VA is a complex intervention to implement and needs leadership and committed country buy-in to succeed.

- Stakeholder engagement is key from senior to frontline workers and for all agencies involved in CRVS. Advocacy should extend throughout this network.

- Understand the current death registration process well and work within this in implementing VA. Several rounds of business process mapping may be needed to uncover the current processes and gain consensus on 'desired' process.

- Scale-up and evaluate gradually so that systems changes can be made incrementally and lessons from pre-test and pilot can be incorporated.

- Technical support teams need to be flexible and work with country teams to incorporate necessary changes to implementation according to country context.

- Long term technical support is needed to facilitate knowledge exchange and navigate information technology infrastructure requirements. Funders should be aware of the length of time necessary for system change.

- For sustainability governments need to be aware of the considerable ongoing investment - particularly for training - necessary to maintain VA capacity and quality.

- Documentation of the lessons and results of VA will assist other countries looking to implement the intervention to better understand their community cause of death.

CRVS, civil registration and vital statistics; VA, verbal autopsy.

lack of monitoring and evaluation during the roll-out phase due to competing needs of the staff during the pandemic, necessitating close support from the $\mathrm{D} 4 \mathrm{H}$ technical team to evaluate and codevelop a road map for the successful scale-up of VA in the country.

In PNG, few staff with the required training and in positions with a specific focus on VA prohibited regular local data analysis and quality assurance. The lack of technical staff with epidemiological and statistical skills in the National Department of Health limits sustainability of monitoring and evaluation activities, analysis of data to present to the National Burden of Disease Committee, and hence the ability for the government to be responsive to the findings. Solutions to capacitate staff are being investigated.

Since the pilot in China was at a relatively smaller scale, training and monitoring could be done more intensively. A technical monitoring group comprising the national-level, provincial-level and district-level CDC held debriefing sessions with the interviewers each day to guarantee the quality of data collection.

In Myanmar, a team from the CSO and the HMIS oversaw the implementation of the intervention, including monitoring, analysis and data quality assurance. The phased approach helped to define the evaluation of the intervention going to scale. Monthly feedback to frontline workers and an annual dissemination and evaluation meeting involving staff from all agencies and at different levels of the system facilitated agreement of 
changes needed for additional scale-up and the sustainability issues related to ongoing operations.

In the Solomon Islands, there is reasonable capacity at national level to oversee quality assurance, including feeding back to provincial health authorities, but providing feedback to interviewers is difficult due to travel and communication barriers and infrequent supervisory visits. Provincial health authorities would ideally conduct their own analysis and quality review but are under-resourced.

\section{CONCLUSIONS}

Scale-up and integration of VA in CRVS is a complex process which requires a staged approach with whole of government involvement. While scale-up recommendations (see box 1) are generic and can be broadly applied, the need for flexibility, adaptation of the tool and approach and incremental steps towards system level change needs to be adapted to the country context. A dedicated technical working group comprising technical experts, government representatives and implementers can plan, advocate, support implementation and promote sustainability. Early stakeholder engagement and codevelopment of the intervention are necessary. Trust needs to be built between the country implementation team and the technical support team, who should be knowledgeable and experienced in VA, so that direction changes can be confidently made along the way, with appropriate documentation. A long lead in time is needed to allow for legislative amendments, changes to job descriptions and standard operating procedures, and scale-up of IT infrastructure, and donors should consider this in supporting such initiatives.

In the current climate of COVID-19, information on causes of death is more critical than ever. VA will be essential to understanding the changing disease patterns precipitated by the pandemic over the coming years. With the right technical and political support, countries can scale up this intervention to ensure ongoing collection of quality and timely information on community deaths. VA for out-of-hospital deaths is vital as an important source of locally generated cause of death data to guide health planning and to monitor national and international targets such as Sustainable Development Goals.

\footnotetext{
Acknowledgements The authors would like to acknowledge the government country partners and the verbal autopsy (VA) interviewers responsible for implementing VA in our D4H countries.
}

Contributors SMF and RJ wrote the first draft. JDH, MR, LM, HL, KSB, DCS, VK, $J-L Q, P Y, A S$ and IR contributed towards the paper. All authors read the final draft. SMF is guarantor.

Funding This study was funded under an award from Bloomberg Philanthropies and the Australian Department of Foreign Affairs and Trade to the University of Melbourne to support the Data for Health Initiative. The funders had no role in study design, data collection and analysis, decision to publish or preparation of the manuscript. $\mathrm{RJ}$ is supported by the Australian National Heart Foundation (APP 102059) and a UNSW Scientia Fellowship.

Competing interests None declared.

Patient consent for publication Not applicable.
Ethics approval Ethics approval was not required because this is a reflection piece by D4H implementers on the lessons from the scale-up of the verbal autopsy (VA) intervention across countries. It does not include any data analysis on the VA data.

Provenance and peer review Not commissioned; externally peer reviewed.

Data availability statement There are no data in this work.

Open access This is an open access article distributed in accordance with the Creative Commons Attribution Non Commercial (CC BY-NC 4.0) license, which permits others to distribute, remix, adapt, build upon this work non-commercially, and license their derivative works on different terms, provided the original work is properly cited, appropriate credit is given, any changes made indicated, and the use is non-commercial. See: http://creativecommons.org/licenses/by-nc/4.0/.

\section{ORCID iD}

Sonja Margot Firth http://orcid.org/0000-0002-2189-0263

\section{REFERENCES}

1 Leitao J, Desai N, Aleksandrowicz L, et al. Comparison of physiciancertified verbal autopsy with computer-coded verbal autopsy for cause of death assignment in hospitalized patients in low- and middle-income countries: systematic review. BMC Med 2014;12:22.

2 Lozano R, Lopez AD, Atkinson C, et al. Performance of physiciancertified verbal autopsies: multisite validation study using clinical diagnostic gold standards. Popul Health Metr 2011;9:32.

3 Institute for Health Metrics and Evaluation. Verbal autopsy tools [online], 2020. Available: http://www.healthdata.org/verbal-autopsy/ tools

4 Serina P, Riley I, Stewart A, et al. Improving performance of the tariff method for assigning causes of death to verbal autopsies. BMC Med 2015;13:291.

5 Hazard RH, Buddhika MPK, Hart JD, et al. Automated verbal autopsy: from research to routine use in civil registration and vital statistics systems. BMC Med 2020;18:60.

6 de Savigny D, Adam T, eds. Systems thinking for health systems strengthening. Alliance for Health Policy and Systems Research. WHO, 2009.

7 de Savigny D, Riley I, Chandramohan D, et al. Integrating community-based verbal autopsy into civil registration and vital statistics (CRVS): system-level considerations. Glob Health Action 2017;10:1272882.

8 Hart JD, Kwa V, Dakulala P. How advanced is the epidemiological transition in Papua New Guinea? New evidence from verbal autopsy. Int J Epidemiol 2021:1. doi:10.1093/ije/dyab088

9 Hart JD, Mahesh P, Kwa V, et al. Diversity of epidemiological transition in the Pacific: findings from the application of verbal autopsy in Papua New Guinea and the Solomon Islands. Lancet Reg Health West Pac 2021;11:100150.

10 Joshi R, Hazard RH, Mahesh PKB, et al. Improving cause of death certification in the Philippines: implementation of an electronic verbal autopsy decision support tool (SmartVA auto-analyse) to aid physician diagnoses of out-of-facility deaths. BMC Public Health 2021;21:563.

11 Mikkelsen L, de Alwis S, Sathasivam S, et al. Improving the policy utility of cause of death statistics in Sri Lanka: an empirical investigation of causes of out-of-hospital deaths using automated verbal autopsy methods. Front Public Health 2021;9.

12 Shawon MTH, Ashrafi SAA, Azad AK, et al. Routine mortality surveillance to identify the cause of death pattern for out-of-hospital adult (aged 12+ years) deaths in Bangladesh: introduction of automated verbal autopsy. BMC Public Health 2021;21:491.

13 Mikkelsen L, de Alwis S, Sathasivam S, et al. Improving the policy utility of cause of death statistics in Sri Lanka: an empirical investigation of causes of out-of-hospital deaths using automated verbal autopsy methods. Front Public Health 2021;9:591237.

14 ESCAP Statistics Division. Regional strategic plan for the improvement of civil registration and vital statistics in Asia and the Pacific (Draft) ESCAP, 2012.

15 World Bank, World Health Organisation. Global civil registration and vital statistics scaling up investment plan 2015-2024. World Bank, 2014.

16 KS B, Firth SM, Hudson S. Advocating for change: how advocacy contributed to strengthened civil registration and vital statistics in Myanmar. CRVS best-practice and advocacy. Melbourne, Australia: Bloomberg Philanthropies Data for Health Initiative, Civil Registration and Vital Statistics Improvement, University of Melbourne, 2020.

17 D4H Technical Working Group. Verbal autopsy interpretation, performance and evaluation resource (viper) v0.9, CRVS resources 
and tools. Melbourne, Australia, Bloomberg Philanthropies data for health Initiative, civil registration and vital statistics improvement: the University of Melbourne, 2019. Available: https://crvsgateway.info/ VIPER

18 D4H Technical Working Group. Guidelines for interpreting verbal autopsy data. CRVS resources and tools. Melbourne, Australia, Bloomberg Philanthropies data for health Initiative, civil registration and vital statistics improvement 2019. Available: https:// crvsgateway_info.myudo.net/file/11243/3231

19 Adair T, Firth S, Phyo TPP, et al. Monitoring progress with national and subnational health goals by integrating verbal autopsy and medically certified cause of death data. BMJ Glob Health 2021;6:e005387.

20 Naing D. End of project evaluation: data for health Initiative. NayPyiTaw, Myanmar: Empower Consulting, 2019. https:// crvsgateway.info/file/17726/3295;

21 Cobos Muñoz D, de Savigny D, Sorchik R, et al. Better data for better outcomes: the importance of process mapping and management in CRVS systems. BMC Med 2020;18:67.

22 Hart JD, Kwa V, Dakulala P, et al. Mortality surveillance and verbal autopsy strategies: experiences, challenges and lessons learnt in Papua New Guinea. BMJ Glob Health 2020;5:e003747.
23 Adair T, Rajasekhar M, Bo KS, et al. Where there is no hospital: improving the notification of community deaths. BMC Med 2020;18:65

24 Qi J, Adair T, Chowdhury HR, et al. Estimating causes of out-ofhospital deaths in China: application of SmartVA methods. Popul Health Metr 2021;19:25.

25 Central Statistical Organisation. Myanmar statistical Yearbook 2020 central statistical organisation, Ministry of planning and finance. Nay Pyi Taw, Myanmar, 2020.

26 Swiss TPH and University of Melbourne. Verbal autopsy budgeting and costing tool. Melbourne, Australia: Bloomberg Philanthropies Data for Health Initiative, Civil Registration and Vital Statistics Improvement, University of Melbourne, 2019. https://crvsgateway. info/file/17116/3144

27 University of Melbourne and Swiss TPH. Verbal autopsy budgeting and costing tool: user guide. CRVS technical guides. Melbourne, Australia: Bloomberg Philanthropies Data for Health Initiative, Civil Registration and Vital Statistics Improvement, University of Melbourne, 2019. https://crvsgateway.info/file/17100/3146

28 Serina P, Riley I, Hernandez B, et al. What is the optimal recall period for verbal autopsies? Validation study based on repeat interviews in three populations. Popul Health Metr 2016;14:40. 